\title{
Transcanal Endoscopic Type 1 Cartilage Tympanoplasty in Children
}

\author{
Doğukan Özdemir (1), Abdulkadir Özgür (1), Gökhan Akgül (1), Mehmet Çelebi (1), \\ Dursun Mehmet Mehel (1), Samet Aydemir (1), Tŭğba Yemiş (1) \\ Department of Otorhinolaryngology, University of Health Sciences Samsun Training and Research Hospital, Samsun, Turkey
}

Abstract

ORCID IDs of the authors: D.0.0000-0003-2008-163X; A. $0.0000-0002-6155-5988$ G.A. 0000-0003-0699-6585; M.C. 0000-0002-0297-3338; D.M.M. 0000-0002-5613-3393; S.A. 0000-0003-3983-1808; T.Y. 0000-0001-8713-0251.

\section{Cite this article as:}

Özdemir D, Özgür A, Akgül G, Çelebi M, Mehel DM, Aydemir S, et al. Transcanal Endoscopic Type 1 Cartilage Tympanoplasty in Children. Turk Arch Otorhinolaryngol 2019; 57(4): 197-200.

\section{Corresponding Author:}

Doğukan Özdemir, drdogukan@hotmail.com

Received Date: 11.06.2019

Accepted Date: 24.09.2019

Content of this journal is licensed under a Creative Commons Attribution 4.0 International License. Available online at www.turkarchotolaryngol.net
Objective: Transcanal endoscopic type 1 tympanoplasty is a minimally invasive procedure that enables better visualization of deep and narrow spaces compared to conventional microscopic methods. In our study, we aimed to evaluate air-bone gap difference, graft success, and hearing gain according to the perforation size and location in pediatric patients who underwent transcanal endoscopic type 1 cartilage tympanoplasty.

Methods: Fifty pediatric patients who underwent transcanal endoscopic type 1 cartilage tympanoplasty for chronic otitis media were included in the study. Tragal cartilage grafts were used in all patients. Air conduction pure tone audiometry hearing results $(500,1000,2000$, and $4000 \mathrm{~Hz})$, mean air-bone gap levels, operating times, postoperative gap closure, and graft success rates were evaluated.
Results: Mean operating time was $43.34 \pm 8.56$ minutes. Overall graft success was 94\% (47/50). Mean hearing levels at all frequencies $(500,1000,2000$, and $4000 \mathrm{~Hz}$ ) were found to have significantly improved after the operation $(\mathrm{p}<0.001)$. Mean preoperative air conduction pure tone threshold and mean air-bone gap had statistically significantly improved by the 6 th postoperative month $(\mathrm{p}<0.001)$.

Conclusion: Transcanal endoscopic type 1 cartilage tympanoplasty was found to be a minimally traumatic, easy and safe method with a low complication rate. In pediatric patients, this method allows for high rates of anatomic and functional recovery with optimal surgery time regardless of the location and the size of the perforation.

Keywords: Tympanoplasty, endoscopic ear surgery, cartilage graft, pediatric tympanoplasty

\section{Introduction}

Tympanic membrane (TM) perforation caused by acute or chronic otitis media which has been reported especially in the first six years of life in children leads to moderate hearing loss in half of the cases (1). Conventional microscopic surgery with limited anterior margin exploration is commonly used in tympanic membrane (TM) reconstruction. However, in the pediatric population, this approach is rather technically challenging and may require an endaural or postauricular incision because of their narrow external ear canal structure compared to those of adults (2). Furthermore, compared to the adult population, lower tympanoplasty success rates, ranging from $35 \%$ to $92 \%$, have been reported in children (3).
The success rate of tympanoplasty is influenced by many factors, including the perforation size and location, the surgical method, the presence of otorrhea, the Eustachian tube function, the presence of adenoid tissue and even the surgeon's experience. Anatomical difficulties are particularly prominent in anterior perforations (1). In addition, the small and narrow ear canal in children results in poor visualization and makes the operation more difficult. In the recent years, transcanal endoscopic type 1 tympanoplasty has been presented as a minimally invasive and safe surgical approach that allows for the visualization of deep and narrow spaces (4). This technique yields the same or even better success rates as the conventional microscopic technique, at the same time is highly effective and less painful with shorter mean operating times (5). 
Regardless of the method, the common treatment goal is to close the perforation with graft material and form an intact, dry TM that provides both anatomic and auditory healing (6). Although many graft materials have been reported to date for this purpose, cartilage and perichondrium tissue have been frequently used and reported as suitable in children (7). In our study, we aimed to evaluate the air-bone gap difference, graft success, and hearing gain according to the perforation size and location in pediatric patients who underwent transcanal endoscopic type 1 cartilage tympanoplasty.

\section{Methods}

\section{Sample}

Following Ethics Committee approval (Apr 30, 2019; 40-2019), the study was conducted at Health Sciences University Samsun Research and Training Hospital, Department of Otorhinolaryngology. The retrospective study included 50 pediatric patients aged under 18 years who underwent transcanal endoscopic type 1 cartilage tympanoplasty for chronic otitis media between December 2016 and January 2019.

Exclusion criteria were absence of ear discharge for at least three months, absence of inflammation and infection in the middle ear mucosa, and absence of any signs of infection in the mastoid air cells in the temporal bone on computed tomography imaging. Revision cases were excluded. Written informed consent was obtained from all patients' families. Ear-nose-throat examinations and pure tone audiometry tests were performed on all patients.

The TM perforation site was classified as anterior, anterosuperior, posterior or subtotal. The membrane perforation sizes were classified as small for perforations smaller than $25 \%$ of the total TM area, medium for perforations between $25 \%$ and $75 \%$, and large for perforations of more than $75 \%$ (8).

\section{Operating procedure}

All patients were operated under general anesthesia using standard $18 \mathrm{~cm}, 0^{\circ}$ endoscopes with $4 \mathrm{~mm}$ and $2.7 \mathrm{~mm}$ diameters (Karl Storz, Tuttlingen, Germany). Local anesthesia was administered on the external ear canal and the tragus (graft donor site) to reduce bleeding. A lateral circumferential incision was made at approximately $3 \mathrm{~mm}$ from the annulus after desepithelization of the perforation margins. The incision was extended superior and inferior to the annulus. The tympanomeatal flap was tilted forward to access the middle ear. The graft was prepared after the control of ossicular mobility. Tragal cartilage was used as graft material. The tragus apex was preserved to prevent cosmetic deformation. At the lateral part of the tragus, about $2 \mathrm{~mm}$ cartilage was spared for contouring. The donor site was sutured with 5.0 Vicryl (polyglycolic acid). The perichondrium on both sides of the graft was preserved. At the lateral part of the tragus, about $2 \mathrm{~mm}$ cartilage was spared for contouring. The cartilage graft was prepared as an island. Cartilage was removed from the area where the malleus was placed, and only the perichondrium was kept in-place. The tragal cartilage was placed with an underlay-overlay technique (under the annulus and over the malleus). The graft was supported medially and laterally with Gelfoam (absorbable gelatin sponge). The time between the endoscopic examination of the TM and the packing of the external ear canal was recorded as the operating time.

Graft success was evaluated as the absence of perforation on postoperative endoscopic examination. Graft success rates, perforation sizes and locations, operating times, air conduction pure tone audiometry and mean air-bone gap measurements before and 6 months after surgery were evaluated.

\section{Statistical Analysis}

All data were analyzed with SPSS (Statistical Package for the Social Sciences) software for Windows (version 21.0; IBM, Armonk, NY, USA). Individual and aggregate data were summarized using descriptive statistics including mean, standard deviation, median (min-max), frequency distribution and percentage. Normality of data distribution was verified by Kolmogorov-Smirnov test. Comparison of the variables with normal distribution was made with Student T Test. Mann Whitney and Kruskal Wallis tests were used for inter-group comparisons among the variables that were not normally distributed. Evaluation of categorical variables was performed by Chi-Square test. $\mathrm{P}$-value $<0.05$ was considered statistically significant.

\section{Results}

Fifty patients, 24 females (48\%) and 26 males (52\%), were included in the study. The mean age was $13.02 \pm 2.65$ years (range: 9-17 years). Operations were performed in the right ear in $44.8 \%(n=22)$, and in the left ear in $56.0 \%(n=28)$ of the patients. Preoperative findings and the air-bone gaps of patients are summarized in Table 1 . The lowest mean air-bone gap was found in the anterosuperior perforation group $(19.75 \pm 5.64$ $\mathrm{dB})(\mathrm{p}=0.174)$. According to perforation size, lower mean airbone gap $(21.21 \pm 7.26 \mathrm{~dB})$ was found in patients with a small $(<25 \%)$ perforation compared to those with a larger perforation $(\mathrm{p}=0.724)$ (Table 1).

All patients were operated under general anesthesia. The mean operating time was $43.34 \pm 8.56$ minutes (range: $28-67 \mathrm{~min}$ ). The graft success rate was $94 \%$ (47/50). Three patients were re-op-

Table 1. Relation between preoperative mean gap and clinical features of the perforations

\begin{tabular}{|c|c|c|c|c|}
\hline & $\begin{array}{l}\text { Clinical } \\
\text { Variables }\end{array}$ & n (\%) & $\begin{array}{l}\text { Preoperative Gap } \\
\text { (Mean } \pm \text { SD) }\end{array}$ & $\mathrm{p}$ \\
\hline \multirow{4}{*}{$\begin{array}{l}\text { Perforation } \\
\text { localization }\end{array}$} & Anterior & $13(26 \%)$ & $20.59 \pm 7.63$ & \multirow[t]{4}{*}{0.174} \\
\hline & Anterosuperior & $11(22 \%)$ & $19.75 \pm 5.64$ & \\
\hline & Posterior & $8(16 \%)$ & $27.15 \pm 7.77$ & \\
\hline & Subtotal & $18(36 \%)$ & $23.51 \pm 6.47$ & \\
\hline \multirow{3}{*}{$\begin{array}{l}\text { Perforation } \\
\text { size }\end{array}$} & $25 \%$ & $15(30 \%)$ & $21.21 \pm 7.26$ & \multirow[t]{3}{*}{0.724} \\
\hline & $25-75 \%$ & $17(34 \%)$ & $22.58 \pm 7.82$ & \\
\hline & $75-100 \%$ & $18(36 \%)$ & $23.51 \pm 9.12$ & \\
\hline
\end{tabular}


Table 2. Comparison of preoperative and postoperative pure tone audiometry measurements

\begin{tabular}{l|c|c|c}
\hline & $\begin{array}{l}\text { Preoperative } \\
(\mathbf{d B})(\mathbf{n}=50) \\
(\text { Mean } \pm \text { SD) }\end{array}$ & $\begin{array}{c}\text { Postoperative (dB) } \\
6^{\text {th }} \text { Month }(\mathbf{n}=47) \\
(\text { Mean } \pm \text { SD) }\end{array}$ & P \\
\hline $500 \mathrm{~Hz}$ & $38.89 \pm 13.37$ & $24.17 \pm 10.29$ & $0.000^{*}$ \\
\hline $1000 \mathrm{~Hz}$ & $35.06 \pm 13.54$ & $23.23 \pm 10.30$ & $0.000^{*}$ \\
\hline $2000 \mathrm{~Hz}$ & $32.09 \pm 12.34$ & $23.72 \pm 10.84$ & $0.000^{*}$ \\
\hline $4000 \mathrm{~Hz}$ & $33.70 \pm 13.37$ & $24.77 \pm 10.15$ & $0.000^{*}$ \\
\hline $\begin{array}{l}\text { Mean air } \\
\text { conduction }\end{array}$ & $34.49 \pm 11.53$ & $22.99 \pm 10.73$ & $0.000^{*}$ \\
\hline Air-Bone Gap & $22.58 \pm 8.11$ & $11.59 \pm 5.78$ & $0.000^{*}$ \\
\hline *: p<0.05 statistically significant; dB: decibel & &
\end{tabular}

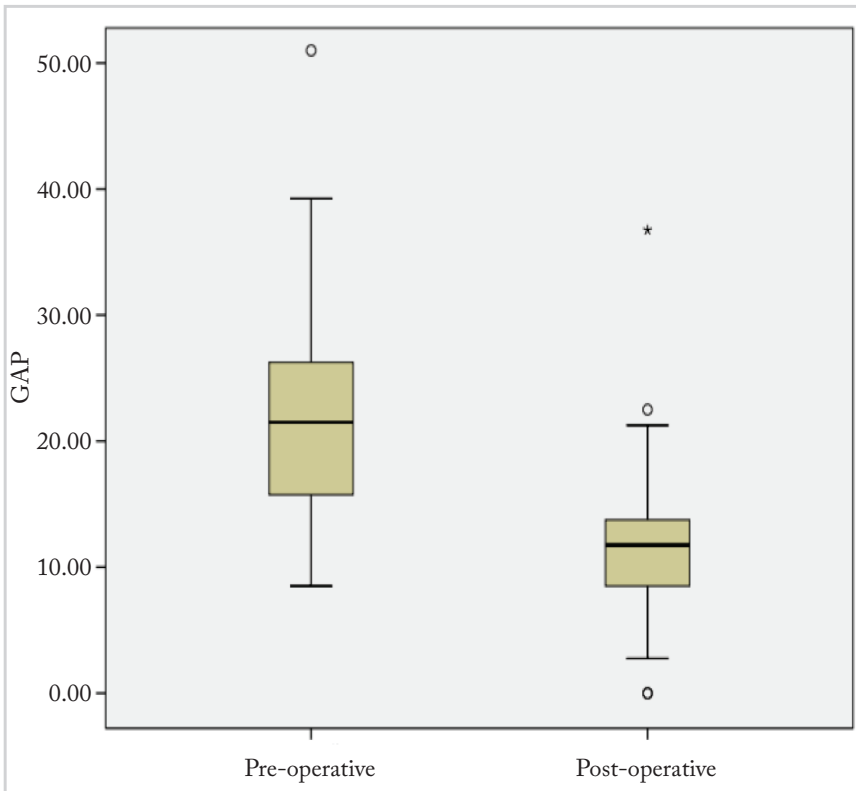

Figure 1. Pre- and post-operative air-bone gaps: mean air-bone gap (pre-op $22.58 \pm 8.11 \mathrm{~dB}$, post-op $11.59 \pm 5.78 \mathrm{~dB}$ ) was statistically significant $(\mathrm{p}=0.000)$

erated on for perforation. The pure tone audiometry measurements at 500,1000,2000, and $4000 \mathrm{~Hz}$ frequencies before and six months after surgery are presented in Table 2 . Preoperative and postoperative hearing levels were compared. The improvement in mean hearing levels at all frequencies were statistically significant $(\mathrm{p}<0.001)$. The improvement in mean air-bone gap (preoperative: $22.58 \pm 8.11 \mathrm{~dB}$; postoperative: $11.59 \pm 5.78 \mathrm{~dB}$ ) was also found statistically significant $(\mathrm{p}=0.000)$ (Figure 1 ).

\section{Discussion}

Although the same tympanoplasty success rates have been reported in some studies in the literature for endoscopic and conventional microscopic tympanoplasties, the endoscopic technique enables narrow and deep visualization in the pediatric population, and provides significant benefits, especially in anterior localized large perforations. Thereby, this technique offers a safer option with shorter and less traumatic surgery in children $(2,5,7)$
A meta-analysis of 564 studies with a minimum follow-up time of six months, including 2609 tympanoplasty-associated pediatric cases, found a mean graft success rate of $83.4 \%$ (9). The researchers noted that the success rate decreased significantly in cases which the perforation area was larger than 50\%. Ribeiro et al. (3) reported $85.7 \%$ anatomical and $76.9 \%$ functional success rates in 91 children with mostly centrally localized perforations $(\mathrm{n}=52)$ and an area of less than $50 \%(\mathrm{n}=66)$. Dündar et al. (10) reported the same success rates in 60 pediatric patients operated on with microscopic and endoscopic methods and noted the short operating time, wide vision and minimally invasive advantages offered by the endoscopic method.

Lee et al. (8) reported results of 423 tympanoplasty cases in which graft success rates and hearing outcomes were better in patients with a small TM perforation $(<50 \%)$ compared to patients with a large perforation ( $>50 \%)$. In contrast, Tseng et al. (11) and Ayache (12) reported that perforation size and localization did not have a statistically significant effect on the graft success rate or the air-bone gap. In a meta-analysis of tympanoplasty-associated data of 4.704 articles, graft success rate was reported to be better by $2.8 \%$ in cartilage grafts versus fascia grafts (13). In the present study, graft success rate was $94 \%(47 / 50)$ at 6 months after surgery, and the perforations were mostly subtotal and anterior located. The mean preoperative gap value was measured at the lowest level in the patient group with $25 \%$ perforation. The location and the size of the perforation did not have a significant effect on mean postoperative air-bone gap closure.

Functional recovery after tympanoplasty in children is as important as anatomic recovery. Bartel et al. (4) reported a statistically significant improvement in the mean air-bone gap (from 15.5 to $6.9 \mathrm{~dB}$ ) and the mean air conduction thresholds (from 24.6 to $16.3 \mathrm{~dB}$ ) levels in the $6^{\text {th }}$ month in 54 pediatric tympanoplasty cases. Ribeiro et al. (3) reported the results of 91 pediatric tympanoplasty patients in whom the mean air conduction threshold was measured $30.8 \pm 11.0 \mathrm{~dB}$ before tympanoplasty and $18.2 \pm 10.5 \mathrm{~dB}$ in the $6^{\text {th }}$ postoperative month, which represents significant improvement. Another study with comparison of endoscopy-guided tympanoplasty with conventional microscopic methods in patients aged between 6 and 15 years $(n=45)$ reported higher airbone gap closure $(6.6 \mathrm{~dB})$ with the endoscopic method, which was found safer and had a low complication rate (2).

In our study, in accordance with literature, the decrease of airway pure tone thresholds at all frequencies, mean airway pure tone and mean air bone gap values measured at 6 months postoperatively were statistically significant. Dündar et al. (10) compared the conventional microscopic method with the endoscopic method in terms of operating time and mean endoscopic surgery time was shorter than the other ( 51.37 vs 67.03 minutes). In a meta-analysis, operating time decreased from 97.12 minutes to 37.99 minutes with the endoscopic method (14). Similarly, in our study, the average operating time was optimal (43.34 \pm 8.56 minutes) despite the poorer visualization of 
the perforation margin and anatomical difficulties in children compared to adults.

\section{Conclusion}

Transcanal endoscopic type 1 cartilage tympanoplasty was found to be a minimally traumatic, easy and safe method with a low complication rate. The method enables high rates of anatomic and functional recovery with optimal surgery times, especially in children, regardless of the location and the size of the perforation. The advantages of endoscopic tympanoplasty method for pediatric membrane repair should be considered.

Ethics Committee Approval: Ethics committee approval was received for this study from the Ethics Committee of Health Sciences University Samsun Research and Training Hospital (Apr 30, 2019; 40-2019).

Informed Consent: Written informed consent was obtained from the parents' of the patients who participated in this study.

Peer-review: Externally peer-reviewed.

Author Contributions: Concept - D.Ö., A.Ö.; Design - D.M.M., S.A.; Supervision - M.Ç.; Data Collection and/or Processing - S.A., T.Y..; Analysis and/or Interpretation - A.Ö., G.A.; Literature Search D.Ö.; Writing - D.Ö.; Critical Reviews - D.Ö., A.Ö.

Conflict of Interest: The authors have no conflicts of interest to declare.

Financial Disclosure: The authors declared that this study has received no financial support.

\section{References}

1. Sarkar S, Roychoudhury A, Roychaudhuri BK. Tympanoplasty in children. Eur Arch Otorhinolaryngol 2009; 266: 627-33. [CrossRef]

2. Nassif N, Berlucchi M, Redaelli de Zinis LO. Tympanic membrane perforation in children: endoscopic type I tympanoplasty, a newly technique, is it worthwhile? Int J Pediatr Otorhinolaryngol 2015; 79: 1860-4. [CrossRef]
3. Ribeiro JC, Rui C, Natercia S, Jose R, Antonio P. Tympanoplasty in children: a review of 91 cases. Auris Nasus Larynx 2011; 38: 21-5. [CrossRef]

4. Bartel R, Levorato M, Adroher M, Cardelus S, Diaz A, Lacima J, et al. Transcanal endoscopic type 1 tympanoplasty in children: cartilage butterfly and fascia temporalis graft. Int J Pediatr Otorhinolaryngol 2019; 121: 120-2. [CrossRef]

5. Choi N, Noh Y, Park W, Lee JJ, Yook S, Choi JE, et al. Comparison of endoscopic tympanoplasty to microscopic tympanoplasty. Clin Exp Otorhinolaryngol 2017; 10: 44-9. [CrossRef]

6. Khan MM, Parab SR. Endoscopic cartilage tympanoplasty: a two-handed technique using an endoscope holder. Laryngoscope 2016; 126: 1893-8. [CrossRef]

7. Nevoux J, Roger G, Chauvin P, Denoyelle F, Garabédian EN. Cartilage shield tympanoplasty in children: review of 268 consecutive cases. Arch Otolaryngol Head Neck Surg 2011; 137: 24-9. [CrossRef]

8. Lee P, Kelly G, Mills RP. Myringoplasty: does the size of the perforation matter? Clin Otolaryngol Allied Sci 2002; 27: 331-4. [CrossRef]

9. Hardman J, Muzaffar J, Nankivell P, Coulson C. Tympanoplasty for chronic tympanic membrane perforation in children: system review and meta-analysis. Otol Neurotol 2015; 36: 796-804. [CrossRef]

10. Dündar R, Kulduk E, Soy FK, Aslan M, Hanci D, Muluk NB, et al. Endoscopic versus microscopic approach to type 1 tympanoplasty in children. Int J Pediatric Otorhinolaryngol 2014; 78: 1084-9. [CrossRef]

11. Tseng CC, Lai MT, Wu CC, Yuan SP, Ding YF. Endoscopic transcanal myringoplasty for anterior perforations of the tympanic membrane. JAMA Otolaryngol Head Neck Surg 2016; 142: 1088-93. [CrossRef]

12. Ayache S. Cartilaginous myringoplasty: the endoscopic transcanal procedure. Eur Arch Otorhinolaryngol 2013; 270: 853-60. [CrossRef]

13. Tan HE, Santa Maria PL, Eikelboom RH, Anandacoomaraswamy KS, Atlas MD. Type I tympanoplasty meta-analysis: a single variable analysis. Otol Neurotol 2016; 37: 838-46. [CrossRef]

14. Lee SY, Lee DY, Seo Y, Kim YH. Can endoscopic tympanoplasty be a good alternative to microscopic tympanoplasty? a systematic review and meta-analysis. Clin Exp Otorhinolaryngol 2019; 12: 145-55. [CrossRef] 